Check for updates

Cite this: RSC Adv., 2018, 8, 29495

Received 28th June 2018

Accepted 5th August 2018

DOI: $10.1039 / \mathrm{c} 8 \mathrm{ra05533e}$

rsc.li/rsc-advances

\title{
Novel encapsulation of water soluble inorganic or organic ingredients in melamine formaldehyde microcapsules to achieve their sustained release in an aqueous environment $\dagger$
}

\author{
Cong Sui, (D) ab Jon A. Preece, (D) ${ }^{c}$ Shu-Hong Yu (DD ${ }^{b}$ and Zhibing Zhang (DD *a
}

\begin{abstract}
A novel type of melamine formaldehyde microcapsule with a desirable barrier has been used to encapsulate water soluble ingredients, including potassium chloride $(\mathrm{KCl})$ and allura red (dye) as models of an inorganic salt and organic molecule, respectively, via a facile method, and it has shown a sustained release of $\mathrm{KCl}$ and allura red for $12 \mathrm{~h}$ and 10 days in aqueous environment, respectively.
\end{abstract}

Microencapsulation is an important technology to stabilise active ingredients and/or control their release for a range of industrial sectors including healthcare, household care, cosmetics and agrochemicals. ${ }^{1-3}$ Various techniques including interfacial polymerisation, in situ polymerisation, solvent evaporation and coacervation, have been developed to encapsulate different types of active ingredients, such as oil-soluble, water-soluble, amphiphilic, powders or cells..$^{4-8}$ Encapsulation of water-soluble active ingredients is usually achieved by forming a water in oil (W/O) emulsion, initially stabilised by the self-assembly of molecular and/or polymolecular surfactants at the liquid/liquid interface, followed by further consolidation through chemical cross-linking of the surfactants at the interface, leading to robust isolatable capsules., ${ }^{2,9}$ The actives that have been encapsulated range from biomacromolecules, such as proteins, ${ }^{3}$ polysaccharides, ${ }^{10}$ and enzymes ${ }^{11,12}$ to small molecules, such as doxorubicin, ${ }^{10,13}$ peroxide, ${ }^{14}$ polyphenols, ${ }^{15}$ and inorganic salts. ${ }^{16,17}$

Melamine formaldehyde (MF) is a versatile chemical crosslinking agent and has been broadly used in a number of encapsulation applications, due to its polycondensates providing a tight seal, thermal and mechanical stability and acid/alkaline resistance. ${ }^{18-20}$ MF polycondensates have been used as shell material to encapsulate oils in applications in the area of carbonless copy paper, ${ }^{21}$ fragrant oil $^{22,23}$ and herbicide/

${ }^{a}$ School of Chemical Engineering, University of Birmingham, UK. E-mail: Z.Zhang@ bham.ac.uk

${ }^{b}$ Division of Nanomaterials \& Chemistry, Hefei National Laboratory for Physical Sciences at the Microscale, Collaborative Innovation of Suzhou Nano Science and Technology, Department of Chemistry, CAS Centre for Excellence in Nanoscience, Hefei Science Centre of CAS, University of Science and Technology of China, Hefei 230026, China

'School of Chemistry, University of Birmingham, Edgbaston, Birmingham B15 2TT, UK $\dagger$ Electronic supplementary information (ESI) available: Experimental section. See DOI: $10.1039 / \mathrm{c} 8 \mathrm{ra05533e}$ insecticide delivery. ${ }^{24}$ However, it has not been possible to form microcapsules, which can encapsulate water soluble ingredients and achieve a sustained release. Herein, we have developed a novel way to synthesise MF microcapsules via an in situ polymerisation process (Scheme 1) with a water soluble inorganic salt (KCl) and an organic dye (allura red), which displayed prolonged release times of $12 \mathrm{~h}$ and 10 days, respectively.

An aqueous phase containing the MF precondensate solution, formaldehyde, poly(acrylamide-acrylic acid) copolymer and the active ( $\mathrm{KCl}$ or allura red) with the $\mathrm{pH}$ adjusted to 4.3, was emulsified within an oil (sunflower oil) phase at a stirring speed of $600 \mathrm{rpm}$ (Scheme 1, Step 1) to form a Pickering emulsion (unripened (low-level cross-linking) microcapsules), with the MF and copolymer acting as the stabilising surfactants

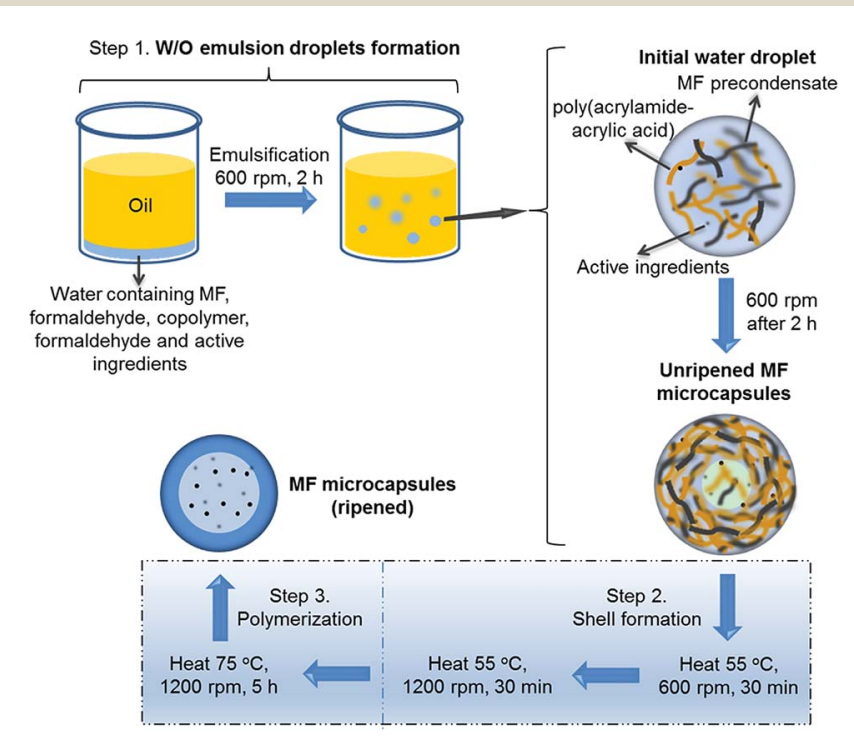

Scheme 1 Illustration of MF microcapsules synthesised via an in situ polymerisation process with water soluble ingredients $(\mathrm{KCl}$ salt/allura red molecules) encapsulated. 
at the liquid/liquid interface. ${ }^{25,26}$ The unripened MF microcapsules were then heated at $55{ }^{\circ} \mathrm{C}$ at $600 \mathrm{rpm}$ for $30 \mathrm{~min}$, which partially solidified the outer shell, ${ }^{27}$ and the stirring speed was then increased to $1200 \mathrm{rpm}$, which was maintained for a further $30 \mathrm{~min}$, to prevent aggregation between the unripened microcapsules (Step 2). The fully ripened MF microcapsules were finally formed by heating at $75{ }^{\circ} \mathrm{C}$ at $1200 \mathrm{rpm}$ for a further $5 \mathrm{~h}$ (Step 3). The MF-KCl microcapsules (ripened) formed with different volumes of formaldehyde solution $(200 \mu \mathrm{l}$ and $600 \mu \mathrm{l}$, $37 \%$ (aq.) w/w) were named as MF-KCl (200 F) and MF-KCl (600 $\mathrm{F})$, respectively.

The W/O emulsion droplets were stabilised by the pre-crosslinked MF precondensate and copolymer at $\mathrm{pH}$ 4.3, which adsorbed at the interface of the emulsion as shown in the optical micrograph (Fig. 1a), forming the unripened $\mathrm{MF}$ microcapsules with a core-shell structure. After preheated at $55{ }^{\circ} \mathrm{C}$ for $30 \mathrm{~min}$, the unripened MF microcapsules partly solidified and they were strong enough to survive when the stirring speed increased to $1200 \mathrm{rpm}$, to avoid aggregation between microcapsules (Fig. S1 $\dagger$ ). The unripened microcapsules maintained their shapes and sizes after the stirring speed was increased as shown in Fig. S1b. $\dagger$ The formed ripened MF$\mathrm{KCl}$ and MF-dye microcapsules showed spherical shapes on the microscale, and the MF-dye revealed a red core under the optical microscope, indicating the encapsulated dye in the MF microcapsules (Fig. $1 \mathrm{~b}$ and c). The $\mathrm{MF}-\mathrm{KCl}(600 \mathrm{~F}$ ) revealed a smoother surface than the $\mathrm{MF}-\mathrm{KCl}(200 \mathrm{~F})$ one, which resulted from the increasing amount of formaldehyde integrated into
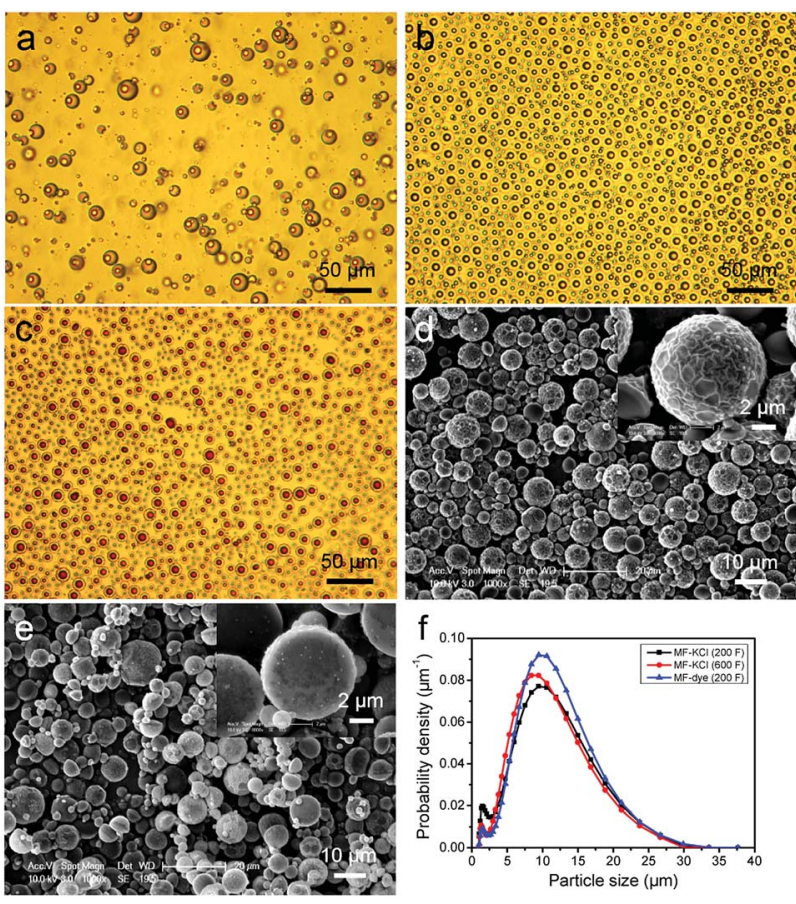

Fig. 1 Optical micrographs of (a) unripened MF-KCl (200 F) microcapsules produced at $600 \mathrm{rpm}$ for $2 \mathrm{~h}$, (b) MF-KCl (200 F) microcapsules and (c) MF-dye (200 F) microcapsules dispersed in water. SEM images of (d) MF- $\mathrm{KCl}(200 \mathrm{~F})$ and (e) MF- KCl (600 F) microcapsules, and ( $\mathrm{f}$ ) the size distributions of $\mathrm{MF}-\mathrm{KCl}(200 \mathrm{~F}), \mathrm{MF}-\mathrm{KCl}(600 \mathrm{~F})$ and (e) MF-dye (200 F) microcapsules. the MF polymerisation process (Fig. 1d and e). The size distributions exhibited in Fig. 1f show similar mean size $[D(4,3)]$ which were around $13 \mu \mathrm{m}$ (Table 1). Clearly, the mean size varied with the viscosity of the prepared aqueous solution, and it slightly decreased with the decreasing viscosity of solution. The three batches of MF samples thus showed similar size distributions.

The cross-sections of MF-KCl (200 F) and MF-KCl (600 F) microcapsules are shown in Fig. 2, indicating clear shell structures. The MF-KCl (200 F) microcapsules displayed a thicker shell $(0.65( \pm 0.04) \mu \mathrm{m}$ to $1.30( \pm 0.09) \mu \mathrm{m})$ with a uniformly distributed core than $\mathrm{MF}-\mathrm{KCl}(600 \mathrm{~F})$ microcapsules (0.59 $( \pm 0.03) \mu \mathrm{m}$ to $1.09( \pm 0.05) \mu \mathrm{m})$ with an inhomogeneously distributed core. The high concentration of formaldehyde in MF-KCl $(600 \mathrm{~F})$ led to the excess amount of formaldehyde in the water phase and might increase the polymerisation rate between MF precondensate and free formaldehyde, forming the unevenly distributed self-assembled solid MF core. Meanwhile, it led to higher local concentrations of formaldehyde, forming a smoother and more compact surface (Fig. 1e). The shell thicknesses of MF-KCl (600 F) microcapsules were thus thinner than those of MF-KCl (200 F) microcapsules due to the less amount of MF assembled in the shell. The elemental compositions of shell and core of $\mathrm{MF}-\mathrm{KCl}(200 \mathrm{~F})$ microcapsules confirmed by the energy dispersive X-ray (EDX) analysis, demonstrate that both of the shell and core contained C, N, Na and $\mathrm{Cl}$, revealing the existing of assembled $\mathrm{MF}$ precondensate and copolymer (Fig. S2 $\dagger$ ). Meanwhile, the detectable K element in the core indicates that the $\mathrm{K}^{+}$ions were encapsulated in the MF microcapsules. The formed MF microcapsules were characterised by the Fourier-transform infrared (FT-IR) spectrometry. The absorption peaks of $\mathrm{N}-\mathrm{H}$ stretching vibration at around 3340, 1559 and $813 \mathrm{~cm}^{-1}$, the $\mathrm{C}-\mathrm{N}$ stretching at around $1358 \mathrm{~cm}^{-1}$, the $\mathrm{C}-\mathrm{H}$ stretching at around 2938 and $1180 \mathrm{~cm}^{-1}$

Table 1 The SPAN and mean size $[D(4,3)]$ of size distributions and viscosity data of initially mixed aqueous solution (before emulsification) for each batch of MF samples. The figure after \pm represents the standard error of the mean

\begin{tabular}{llll}
\hline & $\begin{array}{l}\text { Mean size } \\
\text { Sample }\end{array}$ & & \\
\hline MF-KCl (200 F) & $13( \pm 1)](\mu \mathrm{m})$ & SPAN & Viscosity (Pa s $)$ \\
MF-KCl (600 F) & $12( \pm 1)$ & $1.26( \pm 0.01)$ & $0.0187\left( \pm 7 \times 10^{-4}\right)$ \\
MF-dye (200 F) & $13( \pm 1)$ & $1.26( \pm 0.02)$ & $0.0169\left( \pm 7 \times 10^{-4}\right)$ \\
& & & $0.0188\left( \pm 8 \times 10^{-4}\right)$
\end{tabular}
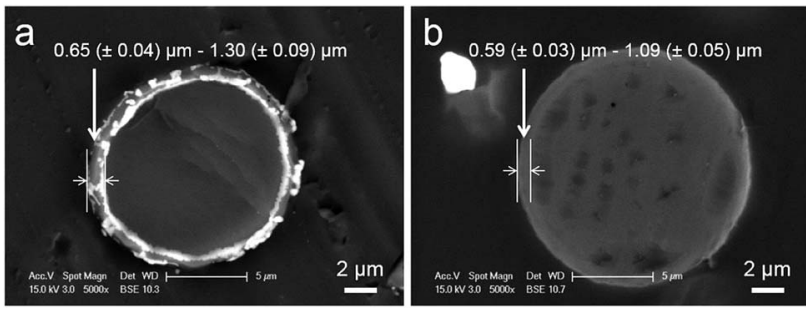

Fig. 2 TEM images of the cross-section of (a) MF- KCl (200 F) and (b) $\mathrm{MF}-\mathrm{KCl}(600 \mathrm{~F})$ microcapsules embedded in epon/araldite resin. (Each data was calculated from at least 30 microcapsules). 
and the methylol at roughly $1010 \mathrm{~cm}^{-1}$, are the characteristics of MF and copolymer. ${ }^{28-30}$ The slight shift of carboxyl group at $1671 \mathrm{~cm}^{-1}$ for $\mathrm{MF}-\mathrm{KCl}$, might be due to the interactions between the carboxyl groups of copolymer and $\mathrm{K}^{+}$ions, relative to the peak at $1663 \mathrm{~cm}^{-1}$ for the neat MF as shown in Fig. S3..$^{31}$

The microcapsules were dispersed in water and the release of $\mathrm{K}^{+}$ions or dye molecules from the microcapsules were monitored, via removal of aliquots at extended time intervals over 12 hours and 10 days, and analysis with flame photometry $\left(\mathrm{K}^{+}\right)$and UV/Vis spectroscopy (dye), respectively. The cumulative release data of $\mathrm{K}^{+}$ ions in Fig. 3a from two batches of MF-KCl microcapsules demonstrates a sustained release within 2 hours, reaching roughly $90 \%$ of the encapsulated ions released out, and then followed by a slow release up to $12 \mathrm{~h}$, which might be due to the interaction between $\mathrm{K}^{+}$and carboxyl groups of copolymer as indicated by FTIR (Fig. S3 $†$ ). Interestingly, the release of $\mathrm{K}^{+}$ions from MF-KCl (600 F) with more content of formaldehyde revealed a slower release rate, which may be attributed to the formed more compact MF, providing a barrier to the encapsulated ions, compared to MF-KCl $(200 \mathrm{~F})$. The release rate of allura red (dye) molecules from MF (200 F) displayed a sustained release, revealing a fast release leaking 36 $\pm 1 \%$ within $2 \mathrm{~h}$ and then slowed down, leaking $56.8 \pm 0.4 \%$ for 10 days (Fig. 3b). The chemical structure of the released allura red (dye) molecules was not checked, since it had been demonstrated to be stable in acidic pH and at temperatures up to $80{ }^{\circ} \mathrm{C} .{ }^{32}$ The payloads and encapsulation efficiencies of $\mathrm{KCl}$ and dye in the $\mathrm{MF}$ microcapsules were calculated using the equations in Experimental section of the ESI† as shown in Table 2. Clearly, the ones for dye in MF microcapsules were higher than for $\mathrm{KCl}$ ions, which probably resulted from the larger molar mass of allura red, and its functional groups (Fig. S4 $\dagger$ ) might interact with MF and the copolymer. Regarding encapsulation of small water soluble ingredients, the commonly used liposomes also exhibited their sustained release for $<24 \mathrm{~h}$ in water, ${ }^{33,34}$ but the obvious drawbacks
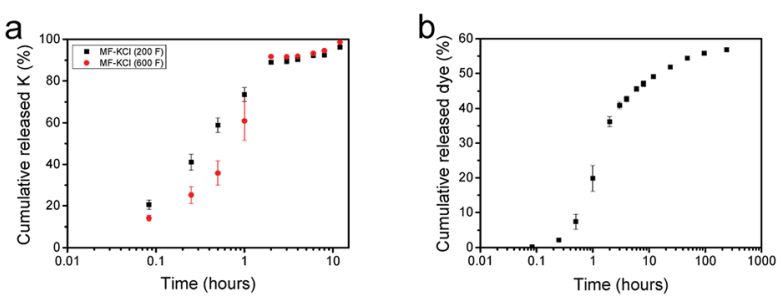

Fig. 3 Cumulative release profiles of (a) $\mathrm{K}^{+}$ions from MF- KCl (200 F) microcapsules, MF-KCl (600 F) microcapsules and (b) dye molecules from MF-dye (200 F) microcapsules dispersed in water at $37^{\circ} \mathrm{C}$ with shaking at a speed of $150 \mathrm{rpm}$. (Each experiment was conducted at least 3 times). are the fast release of the ingredients, high cost, low payload, low reproducibility and instability during storage. ${ }^{35}$ In contrast, the MF microcapsules fabricated here are cheap and reproducible, and they display stable structure for 2 months in ethanol (Fig. S5†).

The mechanical properties of $\mathrm{MF}$ microcapsules were measured by a micromanipulation technique. ${ }^{36}$ A single $\mathrm{MF}$ microcapsule was compressed by two parallel flat surfaces (Fig. 4a and b), and a force versus displacement curve for compression of the single $\mathrm{MF}-\mathrm{KCl}$ (200 F) microcapsule was obtained as shown in Fig. S6. $\uparrow$ The relationship of force $(F)$ versus displacement $(\delta)$ is assumed to represent the elastic behavior, when the nominal deformation calculated by eqn (1) is $\leq 10 \%$, described by the Hertz model as given in eqn (2). ${ }^{37} d$ is the diameter of the microcapsule; $E$ is the Young's modulus of the microcapsules and $v$ is the Poisson's ratio.

$$
\begin{gathered}
\text { Nominal deformation }(\%)=\frac{\delta}{d} \times 100 \\
F=\frac{4}{3} \frac{E}{\left(1-v^{2}\right)} R^{1 / 2}\left(\frac{\delta}{2}\right)^{3 / 2}
\end{gathered}
$$

In this way, a force $v s .(\delta / 2)^{3 / 2}$ curve was fitted with the Hertz model [eqn (2)], see Fig. 4c, and they are in good agreements with a correlation coefficient of 0.99 , which justifies the assumption of the elastic behavior when the nominal deformation is $\leq 10 \%$. The Young's modulus values of the three batches of MF microcapsules are showed in Table 2, and the MF-KCl (200 F) microcapsules formed with the less amount of formaldehyde indicates a higher Young's value due to the thicker shells and uniform cores, relative to the MF-KCl (600 F) microcapsules with an interstitial hollow core. In general, the Young's modulus of the formed MF microcapsules with a range of 2.8-4.9 GPa displayed a similar value, relative to previous researches, and the larger shell thickness could enhance the stiffness of the microcapsule. ${ }^{38,39}$

In conclusion, a novel method to synthesise MF microcapsules with aqueous phase encapsulated was developed in this study, and the water soluble ingredients, including an ion $\left(\mathrm{K}^{+}\right)$ and small molecule (allura red) were encapsulated, indicating a sustained release in water environment for $12 \mathrm{~h}$ and 10 days, respectively. In addition, the formed MF microcapsules displayed Young's modulus values in the order of GPa, revealing comparatively strong stiffness. Therefore, the developed MF formation method may provide a new way to deliver different kinds of water soluble ingredients except those sensitive to acidic $\mathrm{pH}$, which can have applications in different areas of scientific research and industry.

\begin{tabular}{|c|c|c|c|c|}
\hline Sample & $\mathrm{F} / \mathrm{M}$ molar ratio & Payload (\%) & $\begin{array}{l}\text { Encapsulation } \\
\text { efficiency (\%) }\end{array}$ & $\begin{array}{l}\text { Young's } \\
\text { modulus (GPa) }\end{array}$ \\
\hline MF-KCl (200 F) & 0.7 & $7.7( \pm 0.3)$ & $70( \pm 2)$ & $3.3( \pm 0.2)$ \\
\hline MF-dye (200 F) & 0.7 & $8.4( \pm 0.1)$ & $82( \pm 1)$ & $4.9( \pm 0.2)$ \\
\hline
\end{tabular}

Table 2 The F/M (molar ratio), payload, encapsulation efficiency and Young's modulus of each batch of MF samples 

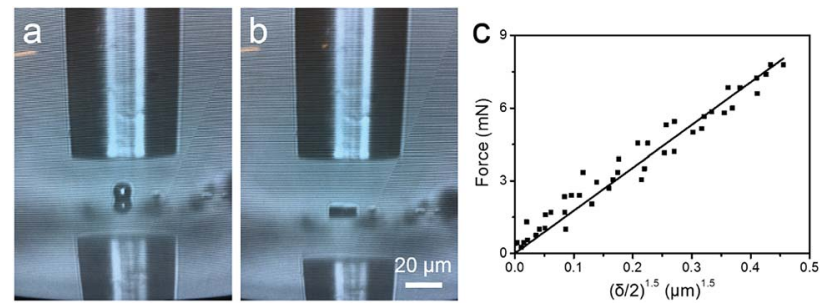

Fig. 4 Optical images obtained from screen (a) before and (b) after compressing a single MF microcapsule to large deformation. (c) The linear fit of the Hertz model to the data from compression of a single $\mathrm{MF}-\mathrm{KCl}(200 \mathrm{~F})$ microcapsule to $10 \%$ nominal deformation of its diameter. The compression speed was $2 \mu \mathrm{m} \mathrm{s}^{-1}$.

\section{Conflicts of interest}

There are no conflicts to declare.

\section{Acknowledgements}

C. S. was fully sponsored by College of Engineering \& Physical Sciences, the University of Birmingham, UK.

\section{Notes and references}

1 R. Ciriminna and M. Pagliaro, Chem. Soc. Rev., 2013, 42, 9243-9250.

2 R. Ciriminna, M. Sciortino, G. Alonzo, A. de Schrijver and M. Pagliaro, Chem. Rev., 2011, 111, 765-789.

3 S. Mitragotri, P. A. Burke and R. Langer, Nat. Rev. Drug Discovery, 2014, 13, 655-672.

4 F. Casanova and L. Santos, J. Microencapsulation, 2016, 33, 117.

5 N. V. N. Jyothi, P. M. Prasanna, S. N. Sakarkar, K. S. Prabha, P. S. Ramaiah and G. Y. Srawan, J. Microencapsulation, 2010, 27, 187-197.

6 B. J. Kim, T. Park, H. C. Moon, S. Y. Park, D. Hong, E. H. Ko, J. Y. Kim, J. W. Hong, S. W. Han, Y. G. Kim and I. S. Choi, Angew. Chem., Int. Ed., 2014, 53, 14443-14446.

7 H. Lee, C. H. Choi, A. Abbaspourrad, C. Wesner, M. Caggioni, T. Zhu and D. A. Weitz, ACS Appl. Mater. Interfaces, 2016, 8, 4007-4013.

8 M. Windbergs, Y. Zhao, J. Heyman and D. A. Weitz, J. Am. Chem. Soc., 2013, 135, 7933-7937.

9 J. Zhang, R. J. Coulston, S. T. Jones, J. Geng, O. A. Scherman and C. Abell, Science, 2012, 335, 690-694.

10 C. Sui, Y. Lu, H. L. Gao, L. Dong, Y. Zhao, L. Ouali, D. Benczedi, H. Jerri and S. H. Yu, Cryst. Growth Des., 2013, 13, 3201-3207.

11 M. J. Abdekhodaie, J. Cheng and X. Y. Wu, Chem. Eng. Sci., 2015, 125, 4-12.

12 P. H. R. Keen, N. K. H. Slater and A. F. Routh, Langmuir, 2014, 30, 1939-1948.
13 Y. Zhao, Z. Luo, M. H. Li, Q. Y. Qu, X. Ma, S. H. Yu and Y. L. Zhao, Angew. Chem., Int. Ed., 2015, 54, 919-922.

14 E. M. Dogan, F. Sudur Zalluhoglu and N. Orbey, AIChE J., 2017, 63, 409-417.

15 A. Elabbadi, N. Jeckelmann, O. P. Haefliger and L. Ouali, J. Microencapsulation, 2011, 28, 1-9.

16 J. Bhaumik, N. S. Thakur, P. K. Aili, A. Ghanghoriya, A. K. Mittal and U. C. Banerjee, ACS Biomater. Sci. Eng., 2015, 1, 382-392.

17 C. Sui, J. A. Preece and Z. Zhang, RSC Adv., 2017, 7, 478-481.

18 D. Chen, H. Zhu, S. Yang, N. Li, Q. Xu, H. Li, J. He and J. Lu, Adv. Mater., 2016, 28, 10443-10458.

19 J. Ge, H. Y. Zhao, H. W. Zhu, J. Huang, L. A. Shi and S. H. Yu, Adv. Mater., 2016, 28, 10459-10490.

20 C. P. Ruan, K. L. Ai, X. B. Li and L. H. Lu, Angew. Chem., Int. Ed., 2014, 53, 5556-5560.

21 M. A. White, J. Chem. Educ., 1998, 75, 1119.

22 A. Ghaemi, A. Philipp, A. Bauer, K. Last, A. Fery and S. Gekle, Chem. Eng. Sci., 2016, 142, 236-243.

23 R. Mercade-Prieto, R. Allen, Z. B. Zhang, D. York, J. A. Preece and T. E. Goodwin, AIChE J., 2012, 58, 2674-2681.

24 M. Pretzl, M. Neubauer, M. Tekaat, C. Kunert, C. Kuttner, G. Leon, D. Berthier, P. Erni, L. Ouali and A. Fery, ACS Appl. Mater. Interfaces, 2012, 4, 2940-2948.

25 A. Schrade, K. Landfester and U. Ziener, Chem. Soc. Rev., 2013, 42, 6823-6839.

26 Y. Long, B. Vincent, D. York, Z. B. Zhang and J. A. Preece, Chem. Commun., 2010, 46, 1718-1720.

27 D. J. Merline, S. Vukusic and A. A. Abdala, Polym. J., 2013, 45, 413.

28 X. D. He, X. W. W. Ge, M. Z. Wang and Z. C. Zhang, Polymer, 2005, 46, 7598-7604.

29 K. Hong and S. Park, Mater. Chem. Phys., 1999, 58, 128-131.

30 N. Seetapan, N. Limparyoon and S. Kiatkamjornwong, Polym. Degrad. Stab., 2011, 96, 1927-1933.

31 P. Lanthong, R. Nuisin and S. Kiatkamjornwong, Carbohydr. Polym., 2006, 66, 229-245.

32 K. Rovina, S. Siddiquee and S. M. Shaarani, Front Microbiol., 2016, 7, 798.

33 J.-Y. Fang, W.-R. Lee, S.-C. Shen and Y.-L. Huang, J. Dermatol. Sci., 2006, 42, 101-109.

34 Q. Lu, D.-C. Li and J.-G. Jiang, J. Agric. Food Chem., 2011, 59, 13004-13011.

35 A. Munin and F. Edwards-Lévy, Pharmaceutics, 2011, 3, 793829.

36 Z. Zhang, R. Saunders and C. R. Thomas, J. Microencapsulation, 1999, 16, 117-124.

37 J. Hu, H.-Q. Chen and Z. Zhang, Mater. Chem. Phys., 2009, 118, 63-70.

38 J. F. Su, J. Qiu, E. Schlangen and Y. Y. Wang, Constr. Build. Mater., 2015, 74, 83-92.

39 R. Mercade-Prieto, R. Allen, D. York, J. A. Preece, T. E. Goodwin and Z. B. Zhang, Chem. Eng. Sci., 2011, 66, 1835-1843. 